\title{
Quantifying delays in the recognition and management of acute compartment syndrome
}

\author{
Christian Vaillancourt, MD;* Ian Shrier, MD, PhD;†† Markus Falk, MSc, PhD;§ \\ Michel Rossignol, MD; $\dagger$ Alan Vernec, MD; $\neq$ Dan Somogyi, MD£
}

\begin{abstract}
Objective: To identify where most efforts should be made to decrease ischemia time and necrosis in acute compartment syndrome (ACS) and to determine the causes for late interventions.

Methods: This was a multicentre, historical cohort study of patients who underwent fasciotomy for ACS within the McGill Teaching Hospitals between 1989 and 1997. Patients studied had a clinical diagnosis of ACS or compartment pressures greater than $30 \mathrm{~mm} \mathrm{Hg}$. In all cases, ACS was confirmed at the time of fasciotomy. Patients were stratified into traumatic and non-traumatic groups, and a step-by-step analysis was performed for each part of the process between injury and operation.

Results: Among the 62 traumatic ACS cases, the longest delays occurred between initial assessment and diagnosis (median time $2 \mathrm{~h} 56$, range from 0 to $99 \mathrm{~h} 20$ ) and between diagnosis and operation (median 2h13, range $0 \mathrm{~h} 15-29 \mathrm{~h} 45)$. Among the 14 non-traumatic ACS cases, delays primarily occurred between inciting event and hospital presentation (median 9h19, range 0h04-289h29) and between initial assessment and diagnosis (median 8h18, range 0-104h15).

Conclusions: ACS is a limb-threatening condition for which early intervention is critical. Substantial delays occur after the time of patient presentation. For traumatic and non-traumatic ACS, increased physician awareness and faster operating room access may reduce treatment delays and prevent disability.
\end{abstract}

\section{RÉSUMÉ}

Objectif : Identifier les endroits où concentrer les efforts pour réduire le délai d'ischémie et la nécrose dans les cas de syndrome compartimental et déterminer les causes des interventions tardives.

Méthodes: Étude historique et multicentrique d'une cohorte de patients ayant subi une fasciotomie pour un syndrome compartimental aux hôpitaux universitaires de McGill entre 1989 et 1997. Les patients à l'étude présentaient un diagnostic clinique de syndrome compartimental ou de compression de la loge supérieure à $30 \mathrm{~mm} \mathrm{Hg}$. Dans tous les cas, le syndrome compartimental fut confirmé au moment de la fasciotomie. Les patients furent répartis en sous-groupes traumatiques et non traumatiques et une analyse étape par étape fut effectuée pour chaque partie du processus entre la blessure et l'intervention.

Résultats : Parmi les 62 cas de syndrome compartimental traumatique, le délai le plus long se produisit entre l'évaluation initiale et le diagnostic (délai médian 2h56, intervalle de 0 à 99h20) et entre le diagnostic et l'intervention (médian 2h13, intervalle 0h15-29h45). Parmi les 14 cas de syndrome compartimental non traumatique, les délais se produisirent principalement entre l'événement causal et la consultation à l'hôpital (médian 9h19, intervalle 0h04-289h29) et entre l'événement causal et le diagnostic (médian 8h18, intervalle 0-104h15).

*Department of Emergency Medicine, Sir Mortimer B. Davis-Jewish General Hospital and Royal Victoria Hospital, McGill University, Montreal, Que.; †Department of Clinical Epidemiology and Community Studies and $¥$ Department of Family Medicine, Sir Mortimer B. Davis-Jewish General Hospital, Montreal; §Chief Information Officer, INOVA Q Inc., Bolzano, Italy; fDepartment of Family Medicine, University of Pittsburgh, Pittsburgh, Pa, USA.

Received: Apr. 25, 2000; final submission: July 25, 2000; accepted: Aug. 23, 2000

This article has been peer reviewed. 
Conclusions : Le syndrome compartimental est une atteinte menaçant l'intégrité des membres pour lequel une intervention précoce est essentielle. Des délais importants se produisent après la visite initiale des patients. Pour les syndromes compartimentaux traumatiques et non traumatiques, une meilleure sensibilisation des médecins et un accès plus rapide à la salle d'opération peuvent permettre de réduire les délais de traitement et prévenir les incapacités.

Key words: compartment syndromes, ischemia, necrosis, time factors

\section{Introduction}

Acute compartment syndrome (ACS) is a limb-threatening condition in which increased pressure within muscle compartments compromises nutrient blood flow to muscles and nerves. ${ }^{1-6}$ Although fasciotomy with direct examination of the muscle compartment is the diagnostic "gold standard" for ACS, the diagnosis is often made clinically and may be confirmed by direct needle measurement of compartment pressure. ${ }^{6-9}$ The only effective therapy is decompression of the affected compartments by fasciotomy. ${ }^{6,10-13}$ If decompression is delayed, muscle necrosis and permanent disability may result. ${ }^{11,14}$

Current knowledge of muscle ischemia tolerance is derived from tourniquet-induced ischemia models, which suggest that muscle can tolerate up to 3 hours of ischemia before necrosis ensues. ${ }^{15-18}$ However, a recent McGill University study of 76 patients who underwent fasciotomy ${ }^{19}$ estimated that $35 \%$ of all ACS patients and $72 \%$ of those who developed necrosis did so within 2 hours of injury — earlier than the 3-hour safe period suggested by ischemia models.

Because ACS patients are at high risk of developing necrosis, it is important to reduce delays to definitive therapy. Our primary objective was to determine the reasons for delayed intervention in cases of acute compartment syndrome. Our secondary objective was to determine whether reasons for delay differed in traumatic and non-traumatic cases.

\section{Methods}

\section{Setting}

This multicentre, historical cohort study was performed at McGill University, Montreal, Canada. It was approved by the ethics committees of all participating hospitals.

\section{Patients}

For medicolegal and remuneration purposes, all fasciotomies performed at the 4 McGill University teaching hospitals are recorded in the hospitals' electronic databases. We used these databases to identify patients who underwent fasciotomy between 1989 and 1997. Because clinically important ACS does not resolve without treatment, and because the only therapy for ACS is fasciotomy, ${ }^{6,10-13}$ we believe this search strategy captured all clinically significant ACS cases that occurred during the study period.

Patients were eligible for inclusion if the treating physician or nurse specifically documented a concern that ACS was present, if compartment pressure measurements $>30$ $\mathrm{mm} \mathrm{Hg}$ were recorded or if ACS was discovered at the time of surgery (e.g., during internal fixation of a fracture). The diagnosis of ACS was accepted only if it was confirmed at fasciotomy. Patients who underwent fasciotomy for reasons other than ACS (e.g., prophylactic fasciotomy prior to vascular bypass surgery or embolectomy ${ }^{20}$ ) were excluded from analysis.

\section{Data collection}

Each chart was abstracted by 1 of 2 physicians (C.V. and D.S.), using a defined process, explicit definitions and specific data abstraction forms to increase reliability. All data forms were double-checked to assure accuracy, and missing data were reported as such. In cases of ambiguous data, consensus agreement was reached between the abstractor and senior author (I.S.). All data were transcribed into an Excel database.

\section{Definitions}

Trauma was defined as any violent contact with the body. Time of injury or inciting event (for traumatic and non-traumatic cases, respectively) was the time documented or estimated in the chart. Time of presentation was defined as the time the patient presented to the enrolling hospital, and time of assessment was when a physician saw the patient. When presentation time was not specified in the nurses' or physicians' notes we used the time of registration (major trauma victims are always seen before they are registered). Time of diagnosis was defined as the time physicians documented a diagnosis in the chart. Time of surgery was defined as the start of anesthesia because this time point is recorded reliably. Confirmation of ACS required a surgeon's report documenting typical findings of ACS (e.g., dusky or grey muscle protruding from a tense fascia, and absent twitch response to stimulation). 


\section{Data analysis}

Intervals studied were: injury-to-hospital presentation, presentation-to-assessment, assessment-to-diagnosis and diagnosis-to-operation. Patients whose inciting event occurred in hospital were excluded from the injury-to-presentation and presentation-to-assessment analyses. Patients whose diagnosis was made in the operating room were excluded from the diagnosis-to-operation analysis. Median values and ranges were calculated for continuous data. Time intervals were compared for traumatic versus non-traumatic cases. The statistical significance of observed differences was determined using the Mann-Whitney U-test for nonparametric data. Calculations were performed using StatView version 5.0 (SAS Institute Inc., Cary, NC).

\section{Results}

Between 1989 and 1997, 237 patients underwent fasciotomy at McGill University teaching centres. Of these, 151 were excluded because fasciotomy was performed for reasons other than ACS (e.g., to access fracture sites, for plantar fascia release in cases of clubfoot or plantar fasciitis). Ten cases

\begin{tabular}{|c|c|}
\hline Characteristic & No. (and \%)* \\
\hline Median age (range), yr & $32(1-80)$ \\
\hline Traumatic etiology & $62(82)$ \\
\hline Male gender & $57(75)$ \\
\hline Associated fracture & $40(53)$ \\
\hline Transferred from referring hospital & $14(18)$ \\
\hline Alcohol or drug intoxication & $12(16)$ \\
\hline Vascular disease present & $11(14)$ \\
\hline Receiving anticoagulant medication & $7(9)$ \\
\hline Injured while in hospital & $7(9)$ \\
\hline
\end{tabular}

Table 2. Time delays in ACS management $(n=76)$

\begin{tabular}{|c|c|c|c|}
\hline & \multicolumn{2}{|c|}{ Median times, hrs:min (range) } & \multirow[b]{2}{*}{$p$} \\
\hline & $\begin{array}{c}\text { Traumatic } \\
(n=62)\end{array}$ & $\begin{array}{c}\text { Non-traumatic } \\
(n=14)\end{array}$ & \\
\hline \multicolumn{3}{|l|}{ Event-to-hospital } & 0.015 \\
\hline Presentation-to-assessment* ${ }^{*}$ & $0: 00(0: 00-1: 38)$ & $0: 26(0: 00-2: 10)$ & 0.036 \\
\hline Assessment-to-diagnosis & $2: 56(0: 00-99: 20)$ & $8: 18(0: 00-104: 15)$ & 0.13 \\
\hline Diagnosis-to-operation $\neq$ & $2: 13(0: 15-29: 45)$ & $3: 07(1: 10-42: 25)$ & 0.20 \\
\hline Total (event-to-operation) § & $9: 47(1: 10-106: 45)$ & $34: 43(7: 00-396: 10)$ & $<0.001$ \\
\hline \multicolumn{4}{|c|}{$\begin{array}{l}\text { * Excludes } 7 \text { patients who were injured while in hospital. } \\
\text { † } 37 \text { of } 62 \text { traumatic cases were assessed immediately; therefore, median delay is } 0: 00 \text {. } \\
\text { ₹ Excludes } 12 \text { patients whose diagnoses were made in the OR. } \\
\text { \$ Total time is not the sum of interval times because median times cannot be added. }\end{array}$} \\
\hline
\end{tabular}

of ACS associated with necrotizing fasciitis were also excluded because, in these cases, muscle necrosis could not be solely attributed to ACS. Table 1 summarizes baseline characteristics of the 76 patients who were eligible for analysis. Of interest, only 34 of these 76 patients had compartment pressures measured. In both traumatic and nontraumatic groups, the diagnosis of ACS was usually made on clinical grounds.

Table 2 illustrates where time delays occurred. Note that 7 patients whose inciting event occurred in the hospital were excluded from the injury-to-hospital and presentation-toassessment analyses. These 7 events included intravenous infiltration (1), surgical correction of genu valgus (1), intraaortic balloon insertion (1), angioplasty catheter insertion (1) and internal fixation of a fracture (3). Twelve patients were excluded from the diagnosis-to-operation analysis because their diagnosis was made in the operating room (OR) during surgery for another reason (e.g., fracture fixation).

Of the 14 non-traumatic cases, 6 occurred after muscular exertion, 6 after prolonged immobility in the context of a drug overdose, 1 was related to Ehlers-Danlos syndrome, and 1 was due to eosinophilic fasciitis.

The data show that post-traumatic ACS cases present to hospital rapidly (about 1 hour) after the causative event compared with more than 9 hours for non-traumatic cases. This was true despite the fact that 14 of our patients required transfer from peripheral hospitals. After presentation, traumatic cases waited less for assessment (median delay $=0$ vs. $26 \mathrm{~min} ; p=0.036$ ). Although the difference is not statistically significant, trauma cases also had shorter assessment-to-diagnosis intervals ( $2 \mathrm{~h} 56 \mathrm{vs.} 8 \mathrm{~h} 18 ; p=0.13$ ) and shorter diagnosis-to-operation intervals (median = $2 \mathrm{~h} 13$ vs. 3 h08; $p=0.20$ ).

Three patients experienced extraordinary long diagnosisto-operation times. One of these patients was waiting for open-heart surgery, and fasciotomy was deferred $28 \mathrm{~h} 25$ so both procedures could be performed during a single anesthetic. A second patient waited $42 \mathrm{~h} 25$ between diagnosis and fasciotomy because a resident failed to notify the attending orthopedist of the diagnosis. In the final case, physicians waited $29 \mathrm{~h} 45$ after ACS diagnosis to perform fasciotomy at the same time as open reduction and internal fixation. 


\section{Discussion}

The longest delays in patients with traumatic ACS occurred because of failure to make an early diagnosis and inability to mobilize the operating room. Delays in non-traumatic cases were primarily due to late hospital presentation and failure to make a timely diagnosis. In both forms of ACS, the diagnosis is often not suspected or not promptly recognised by emergency physicians and admitting services.

These results confirmed our clinical suspicion that traumatic cases are assessed, diagnosed and treated more rapidly than non-traumatic cases. There are several likely reasons for this. Trauma victims present acutely to the ED, often by ambulance; whereas patients with non-traumatic ACS are likely to delay seeking care, perhaps because of insidious symptom progression or perhaps with hopes that symptoms will subside. In addition, physicians see traumatic cases more quickly after ED arrival,. This is not surprising. ED physicians repeatedly learn the importance of "the golden hour" in trauma care and have been indoctrinated into the trauma team mentality.

Delayed assessment of non-traumatic ACS may also reflect a shortfall in existing triage protocols. For instance, the Canadian Emergency Department Triage and Acuity Scale $(\mathrm{CTAS})^{21}$ recommends that major trauma victims be seen immediately but that patients presenting with non-traumatic extremity pain can wait 15 minutes if the pain is severe $(>8 / 10)$ and 1 hour if the pain is moderate (4-7/10). Although these recommendations are appropriate in most cases, triage personnel should be alerted to exceptions. We therefore suggest educational efforts to increase the awareness of ACS.

Many consider ACS to be exclusively a trauma-related condition. In this series, however, we documented 14 nontraumatic cases. Therefore, even in the absence of trauma, physicians should think of ACS in patients who have pain out of proportion to physical findings ("out of proportion" may be difficult to judge, however, since patients have variable pain thresholds and emergency physicians seldom know the patients they treat). Useful signs to confirm ACS include pain on passive muscle stretch, palpable compartment tenseness, weakness of the affected muscles, hypoesthesia in the distribution of nerves traversing the compartment, and loss of pedal pulses. ${ }^{5,11,14}$ It is important to note, however, that loss of pulses and neurological function are late signs and that the diagnosis should be made before these occur.

Pressure measurement is an important emergency medicine skill, and emergency physicians should consider checking compartment pressures in cases of suspected ACS. Physicians should also recognise that ACS is a dynamic condition, that compartment pressures change over time, and that the extent of tissue ischemia depends on regional perfu- sion pressure - the difference between diastolic pressure and intracompartment pressure. ${ }^{10}$ Borderline compartment pressures over $20 \mathrm{~mm} \mathrm{Hg}$ may cause vascular compromise and should trigger follow-up measurements, while pressures $>30 \mathrm{~mm} \mathrm{Hg}$ are considered diagnostic of ACS.

Given the importance of rapid treatment, the prolonged diagnosis-to-operation intervals seen in this study are concerning. Reasons for delay may include poor operating room (OR) time management and absence of reserved OR time for emergencies. ${ }^{22-25}$ We suspect, in addition, that physicians have been falsely reassured by tourniquet studies, which have suggested that muscle can tolerate up to 3 hours of ischemia. ${ }^{15-18}$ However, tourniquet-induced ischemia may be less damaging than ACS-induced ischemia. In the only study to address this possibility, Heppenstal and associates ${ }^{16}$ found that $\mathrm{pH}$ and phosphocreatine recovered rapidly and fully in dogs subjected to tourniquet-ischemia, but only slowly and partially in ACS-induced ischemia. Cellular ATP (adenosine triphosphate) remained normal in the tourniquet group, whereas it decreased and never recovered completely in the ACS group. Finally, ultrastructural degeneration in the skeletal muscle was more common and more severe in the ACS group. These results suggest that we cannot generalize studies of tourniquet-induced ischemia to patients with ACS.

\section{Limitations}

This study suffers from the shortfalls inherent in its retrospective design. A prospective study could have provided more accurate and extensive clinical information, but ACS is an uncommon condition and such conditions are difficult to study prospectively. In addition, it is likely that a prospective study would have increased ACS awareness, changed practice patterns and decreased the door-to-surgery time, introducing a Hawthorne effect and limiting the validity of the results. We feel that, despite its limitations, a historical cohort design was the best method for this study.

We documented long delays from event-to-presentation and, in some cases, from diagnosis-to-operation. Depending on the degree of ischemia and rate of progression, these delays may or may not have contributed to adverse patient outcomes. Unfortunately, in a retrospective review it is difficult to gather reliable clinical status information; therefore we can only suggest that delays seemed excessively long, not that they caused harm in specific cases.

Because we studied patients in university teaching hospitals, referral bias may have occurred, and patients in this study may differ from those seen in smaller community hospitals. In addition, diagnosis-to-surgery delays may differ in different settings, depending on local expertise and OR availability.

Given the retrospective nature of the study, we may be 
unaware of important confounding events. For example, in 4 cases, we learned that casts had been applied between the time of the injury and the ACS diagnosis. In these cases, the cast application (rather than the injury) may have caused the ACS ${ }^{6}{ }^{66}$ Had we known the time of cast application, we might have determined a shorter time interval between inciting event and onset of necrosis. ${ }^{19}$

Finally, when patients were transferred from peripheral hospitals, we considered the times of presentation and assessment to be the times at the referral centres. If we had used peripheral hospital times, the intervals from presentation-to-assessment, assessment-to-diagnosis and diagnosisto-operation would have been different. Consequently, our results may underestimate the true delays for some patients.

\section{Conclusions}

Acute compartment syndrome is a limb-threatening condition for which early intervention is critical. Tissue necrosis may begin earlier than the 3 hours suggested in prior studies. Emergency physicians should be aware of ACS symptoms and signs, and should be capable of measuring compartment pressure in cases where the diagnosis is unclear.

Presented in part at the American College of Emergency Physicians Research Forum, San Diego, Calif., USA, October 1998, and the Canadian Association of Emergency Physicians/Association des médecins d'urgence du Québec Joint Conference, Quebec, Que., October 1999.

\section{References}

1. Ashton $\mathrm{H}$. Effect of inflatable plastic splints on blood flow. $\mathrm{Br}$ Med J 1966;2:1427-30.

2. Reneman RS, Slaaf DW, Lindbom L, Tangelder GJ, Arfors K-E. Muscle blood flow disturbances produced by simultaneously elevated venous and total muscle tissue pressure. Microvasc Res 1980;20:307-18.

3. Shrier I, Magder S. Pressure-flow relationships in an in vitro model of compartment syndrome. J Appl Physiol 1995;79:214-21.

4. Shrier I, Magder S. Critical closing pressure and arterial resistance in an in vitro model of compartment syndrome. Med Sci Sports Exerc 1994;26(Abstract suppl.):S162.

5. Ruiz E. Compartment syndromes. In: Tintinalli JE, Ruiz E, Krome RL, editors. Emergency medicine: a comprehensive study guide, 4th ed. New York: McGraw-Hill; 1996. p. 1307-11.

6. Menetrey J, Peter R. Syndrome de loge aigu de jambe post-traumatique. Rev Chir Orthop Reparatrice Appar Mot 1998;84:272-80.

7. Amendola A, Rorabeck CH, Vellett D, Vezina W, Rutt B, Nott 1 . The use of magnetic resonance imaging in exertional compartment syndromes. Am J Sports Med 1990;18:29-34.

8. Balduini FC, Shenton DW, O'Connor KH, Heppenstall RB. Chronic exertional compartment syndrome: correlation of compartment pressure and muscle ischemia utilizing 31P-NMR spectroscopy. Clin Sports Med 1993;12:151-65.
9. Styf JR, Körner LM. Microcapillary infusion technique for measurement of intramuscular pressure during exercise. Clin Orthop 1986;207:253-62.

10. Mabee JR. Compartment syndrome: a complication of acute extremity trauma. J Emerg Med 1994;12(5):651-6.

11. Matsen FA, Winquist RA, Krugmire R. Diagnosis and management of compartment syndromes. J Bone Joint Surg [Am] 1980; 62:286-91.

12. Rorabeck CH, Clarke KM. The pathophysiology of the anterior tibial compartment syndrome: an experimental investigation. J Trauma 1978;18:299-304.

13. Welbourn CRB, Goldman G, Paterson IS, Valeri CR, Shepro D, Hechtman HB. Pathophysiology of ischaemia reperfusion injury: central role of the neutrophil. Br J Surg 1991;78:651-5.

14. Good LP. Compartment syndrome: a closer look at etiology and treatment. AORN J 1992;56:904-11.

15. Haljamäe H, Enger E. Human skeletal muscle energy metabolism during and after complete tourniquet ischemia. Ann Surg 1975;182:9-14.

16. Heppenstall RB, Scott R, Sapega A, Park YS, Chance B. A comparative study of the tolerance of skeletal muscle to ischemia. $\mathrm{J}$ Bone Joint Surg [Am] 1986;68:820-8.

17. Miller SH, Price G, Buck D, Neeley J, Kennedy TJ, Graham WP, et al. Effects of tourniquet ischemia and postischemic edema on muscle metabolism. J Hand Surg 1979;4:547-55.

18. Sapega A, Heppenstall RB, Chance B, Park YS, Sokolow D. Optimizing tourniquet application and release times in extremity surgery: a biochemical and ultrastructural study. J Bone Joint Surg [Am] 1985;67:303-14.

19. Vaillancourt C, Shrier I, Falk M, Rossignol M, Vernec A, Somogyi D. Acute compartment syndrome: a tissue survival analysis [abstract]. CJEM 1999;1(3):190.

20. Quinn RH, Ruby ST. Compartment syndrome after elective revascularization for chronic ischemia. Arch Surg 1992;127:865-6.

21. Beveridge R, Clarke B, Janes L, Savage N, Thompson J, Dodd G, et al. Canadian Emergency Department Triage and Acuity Scale: implementation guidelines. CJEM 1999;1 (3 Suppl).

22. Ramesh S, Dehn TC, Galland RB. A traumatic deterioration in general surgeons' access to emergency theatre. Ann R Coll Surg Engl 1997;79 (2 Suppl):66-7.

23. Lovett BE, Katchburian MV. Emergency surgery: half a day does make a difference. Ann R Coll Surg Engl 1999;81:62-4.

24. Dexter F, Macario A, Lubarsky DA, Burns DD. Statistical method to evaluate management strategies to decrease variability in operating room utilization: application of linear statistical modeling and Monte Carlo simulation to operating room management. Anesthesiology 1999;91:262-74.

25. Overdyk FL, Harvey SC, Fishman RL, Shippey F. Successful strategies for improving operating room efficiency at academic institutions. Anesthesia Analgesia 1998;86:896-906.

26. Styf J, Wiger P. Abnormally increased intramuscular pressure in human legs: comparison of two experimental models. J Trauma 1998;45:133-9.

Correspondence to: Dr. Ian Shrier, Department of Clinical Epidemiology and Community Studies, Sir Mortimer B. Davis-Jewish General Hospital, 3755, chemin côte Ste-Catherine, Montreal QC H3T 1E2; tel 514 340-4562, ishrier@med.mcgill.ca 